\title{
CROSS-COUNTY INTERNAL MIGRATION AND CONVERGENCE IN ROMANIA
}

\author{
Daniela Bunea ${ }^{l}$
}

\begin{abstract}
Research on internal migration can be divided into two directions: identifying its determinants and/or assessing its consequences. Migration is bidirectional. i.e. can be affected by and can affect socio-economic disparities within a country. On one hand, the determinants of internal migration can be numerous and their analysis is very complex and, on the other hand, migration should have, at least theoretically, some influence on income and unemployment convergence, i.e. disparities reduction. The objectives of this paper are to evaluate the level of internal migration in Romania using county data and to assess its impact on convergence, using various methods, both statistical and econometric. The main results point out at: very low levels of migration and relative small differences among them, no influence of migration on GDP divergence and extremely low on unemployment convergence.
\end{abstract}

Keywords: internal migration, inequality indexes, convergence, non-linear model, panel data model

JEL Codes: J61, R11, R15

\section{Introduction}

Romania is divided into 8 regions of development (NUTS 2) and 42 counties, including the capital Bucharest (NUTS 3), according to Eurostat NUTS classification. (The NUTS classification is a hierarchical system for dividing up the economic territory of the EU for the purpose of collecting, developing and harmonizing EU regional statistics; making socio-economic analyses of the regions and framing the EU regional policies - http://epp.eurostat.ec.europa.eu/portal/page/ portal/nuts_nomenclature/ introduction).

The regions of development are named by their geographical position: North-East (NE), South-East (SE), South (S), South-West (SW), West (W), North-West (NW), Centre (C) and Bucharest-Ilfov (BI). Each region is divided into more counties, as can be seen in figure 1.

According to the Romanian National Institute of Statistics, the average land area of a county in Romania is $5,809 \mathrm{~km}^{2}$, with the county of Timiş $\left(8,697 \mathrm{~km}^{2}\right)$ the largest one and the county of Ilfov $\left(1,583 \mathrm{~km}^{2}\right)$ the smallest one. As for the average population, this rounds the value of 511,200 inhabitants (1 July 2009), with Iaşi as the most populous (829,973 inhabitants) and Covasna (222,710 inhabitants) as the least populous county. Finally, as for the density (nationally, 90.1 inhab./ $\mathrm{km}^{2}$ ), the densest populated is Ilfov (197.3 inhab./ $\left.\mathrm{km}^{2}\right)$ and the least densely is Tulcea (29.1 inhab. $/ \mathrm{km}^{2}$ ). (Nevertheless, in the rankings above, the capital Bucharest is the most populous $\left(1,944,226\right.$ inhab.), the smallest $\left(88 \mathrm{~km}^{2}\right)$ and the densest populated $\left(8,169\right.$ inhab./ $\left.\mathrm{km}^{2}\right)$ county.)

\footnotetext{
${ }^{1}$ Bucharest Academy of Economic Studies, e-mail: daniela.bunea@yahoo.com
} 


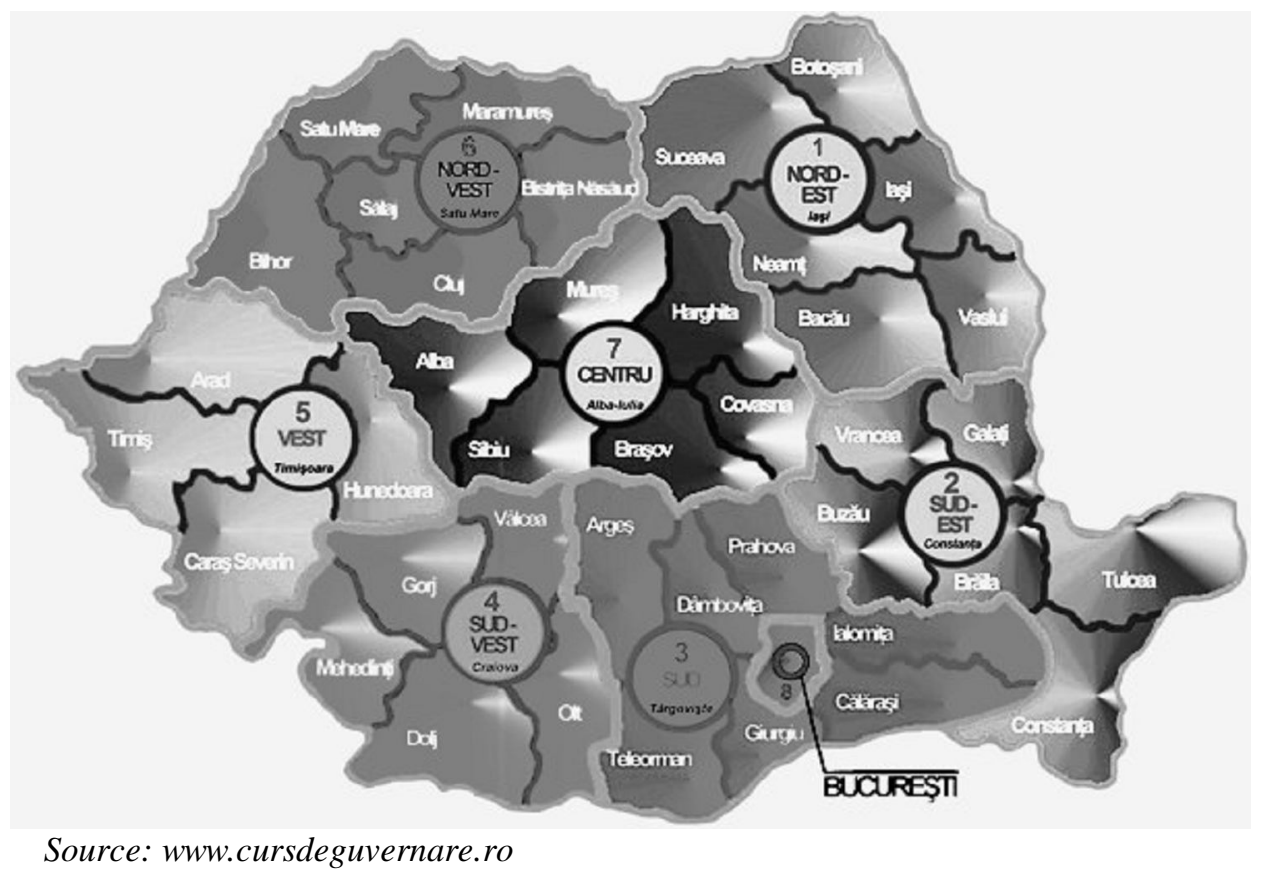

Figure no 1. - Regions and counties of Romania

\section{Literature review on internal migration}

Migration is not a random process. It is a rational choice that implies two decisions: to migrate and where to migrate. The first represents the microeconomic approach, while the second refers to the macroeconomic approach. They are both independent and sequential decisions. The purpose of the micro approach is the individual's behaviour and the factors which influence its migration decision; instead, the macro approach refers more to places rather than people and to aggregate flows of migrants. Migration comprises three main contents:

$\Rightarrow$ spatial context distinguishes between internal and international migration;

$\Rightarrow$ modelling context distinguishes between micro and macro approaches;

$\Rightarrow$ objective context distinguishes between identifying the determinants of migration and exploring the consequences of migration (Etzo, 2008).

Migration can take two forms: speculative migration and contracted migration. The former consists in searching for a job in another place, while the latter is provoked by already finding a job in another place (Silvers, 1977). Molho (1986) considers that speculative migration is part of the job-search process whereas contracted migration is the result of this process.

In the literature there are two perspectives on internal migration: the disequilibrium perspective and the equilibrium perspective. The former argues that migration is due to the existence of regional salaries that do not clear the market, whereas the latter considers that regional variations do clear the market. Although both views consider spatial variations of utility that underlie migration, they differ in the source and persistence of these variations (Greenwood, 1997).

In 1885 and 1889, English geographer Ernest Ravenstein, in its attempt to understand the dynamics of domestic migration, formulated the following "Laws of Migration"2:

- migration is greatly on short distances towards big cities, and long-distance migrants prefer big cities;

- women migrate more than men;

- expanding towns are populated by migrants from rural neighboring areas;

- $\quad$ big cities increase their population more by migration than by natality;

- migration produces in stages and not instantaneously;

- rural inhabitants are more eager to migrate than urban inhabitants, and migrants, in their

\footnotetext{
${ }^{2}$ Using the data of the census from England and Wales.
} 
majority, move from villages to towns;

- each migratory stream produces an opposite movement called counterstream (although not of the same volume);

- migrants are mainly adults;

- socio-economic development boosts migration;

- migration has, mainly, economic causes, such as better employment and gaining opportunities at the destination.

Later on, Everett Lee (1966), conceptualized the push-pull theory in which factors push and factors pull are the main determinants of migration. More accurate, unfavorable conditions in the origin area push people to out-migrate whereas favorable conditions at the destination pull inmigrants. Moreover, he also outlined the impact of variables such as distance, physic and political barriers, and the existence of dependents, which can difficult or even deter migration. Lee thinks that the process of migration is selective because differences in age, sex and social class affects migrants' reaction to push-pull factors and their ability to overcome obstacles. Also, personal features as education, knowledge of the possible destination, family and kinship ties, etc. can facilitate or delay migration.

The Harris-Todaro model (1970) argues that migration is motivated by expected earnings differentials between rural and urban areas, adjusted for the probability of finding employment at destination. Rural-to-urban migration in the context of a high urban unemployment is an economically rational decision if the expected urban income exceeds the expected rural income. Equilibrium will be reached when urban wage will equal rural labour marginal product. In the rural sector there is no unemployment while in the urban sector there will always be some unemployment (Riadh, 1998). Expanding this model at international scale is easy to understand why many citizens from Central and Eastern Europe, with growing populations, choose to migrate to the western part of the EU where wages and employment are relatively higher.

The gravity model postulates that migration is positively correlated with origin and destination population and negatively correlated with the physic distance between them (Wissen et al., 2003). This is the most popular model to analyze migration, although with some extended modifications.

Migration can be considered individually or aggregately. For instance, family migration, usually, has different implications on each family member's income. Migration is opportune when family, as a whole, experiences a net gain in total income. This could happen even if the earnings of one member fall very much as a consequence of the move, as long as the relative earnings of the other member(s) increase. In other words, the optimal decision for the family is not necessarily the same optimal decision for each member. This gave rise to undecided migrants. Tied stayer is that member that sacrifices better employment prospects elsewhere because for his (her) partner is more convenient to remain in the current location. Tied mover is that member who follows his (her) partner in spite of her (his) own better opportunities at home, because the net gain of the family increases (Borjas, 2008).

In the literature, there are a few theories of internal migration, among which: the neoclassical theory, the job-search (or job-matching) theory and the Keynesian theory. In 1932, Nobel price winner, John Hicks, stated that "differences in net economic advantages, chiefly differences in wages, are the main causes of migration" (p. 76). This statement was the starting point of all modern analysis on migration and constitutes the basis of the neoclassical theory of migration. According to this, people decide to move only if expected gains exceed costs of moving (both monetary and non-monetary ${ }^{3}$ ) (Borjas, 2008). If the neoclassical theory argues that migration takes place before finding a job at destination, the job-search (job-matching) theory argues that migration occurs after having already a job in hand. While job-search theory considers individual

\footnotetext{
${ }^{3}$ Transportation costs, foregone earnings during moving, psychic costs of leaving family and friends, accommodation costs etc.
} 
decision, job-matching theory considers aggregate decision. The human capital (neoclassical) model cannot explain by itself the migration process because it assumes that information is costless. So, the migration decision should be taken in two stages: first, to migrate or not, taking into account the costs involved; second, to accept or not a certain job (Jackman and Savouri, 1992). Finally, the Keynesian theory is critical against the neoclassical one due to the different view on money. In the first theory, labour supply depends not only on real wage (as the second theory), but also on nominal wage. From the neoclassical point of view money is just a medium of exchange, while from the Keynesian point of view money is both a medium of exchange and medium of saving. Due to this last function, migrants are also attracted by high nominal wage regions. Moreover, if in the neoclassical approach migration reduces real wage disparities among regions, in Keynesian approach migration reduces rather unemployment disparities (Jennissen, 2007).

Although it may seem that migration has only economic motivation, most empirical studies revealed that there is a series of determinants, subjective and objective. The subjective factors are individual and family features of potential migrants, such as: age, sex, marital status, educational attainment, entrance on labour force, beginning a career, owing a house, leaving parental home, retirement, private earnings, dependents, labour market status (employed, unemployed, inactive), accumulated skills, occupational tenure, health, etc.. The objective factors are various relative characteristics of origin and destination regions, among which: conditions of local labour market (wages, unemployment, etc.); conditions of local real estate market; local taxes and expenditure; public goods availability; topological, climatic and environmental conditions; distance; degree of urbanization, etc.

\section{Evolution of county internal migration}

First of all, internal migration uses a specific glossary of terms. Gross migration is the number of people moving across different areas of a nation, or the total number of in-migrants and out-migrants within a nation. In-migration represents people moving into one place from another, and out-migration people moving out of one place to another. Net migration or migration balance is the difference between in-migrants and out-migrants. Gross migration rate constitutes the ratio of (a) the number of migrations from an area during a specific period to (b) that area's population in the previous period, multiplied by 1000; meanwhile, net migration rate is the ratio of (a) net migration for an area during a specific period to (b) its population in the previous period, multiplied by 1000 .

If rates are negative it means more people leaving the area than entering it. Otherwise, more people enter the area than leave it.

\section{a. Regional internal migration}

During the period 2004-2009, only the regions Bucharest-Ilfov (6,956 migrants), West $(3,085)$ and North-West $(546)$ had positive average balances, while North-East $(-5,623)$ and SouthWest $(-2,242)$ registered the highest negative values (fig. 2). North-East and South experienced a high number of out-migrants, although NE, together with Bucharest-Ilfov, also received the most in-migrants. Centre and West recorded the lowest number of migrants, both out and in.

As for the net migration rates, Bucharest-Ilfov (3.13\%o), West (1.59\%o) and North-West $(0.2 \% o)$; North-East $(-1.51 \%$ ) and South-West $(-0.97 \%$ ) were also the regions with the highest values (fig. 2). 


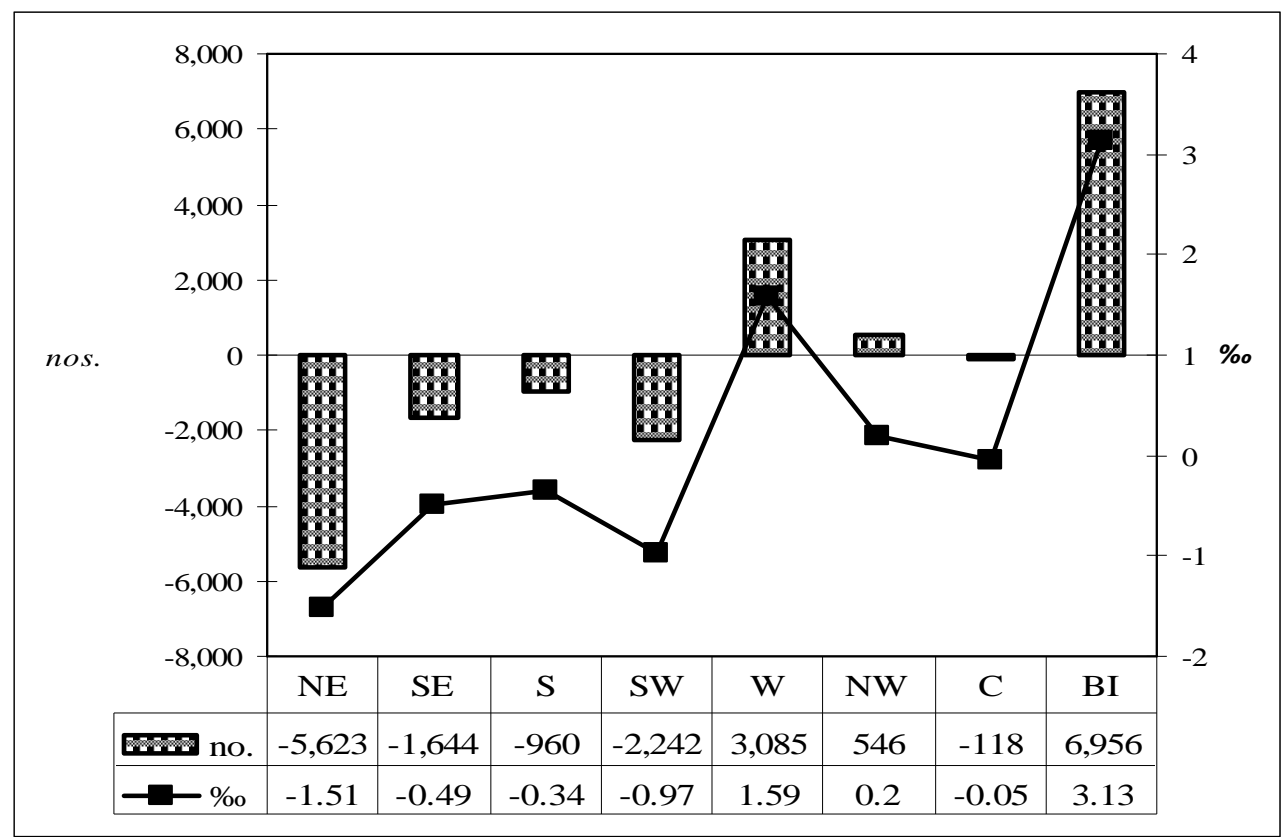

Figure no. 2. Regional migration balance (average nos. and rates) 2004-2009 Source: Romanian Statistical Yearbook 2005-2010/Ch. 2. Population

\section{b. County internal migration}

During the period 2004-2009, Bucharest, Iaşi and Constanţa experienced the highest number of out-migrants; Bucharest and Constanța also had the most in-migrants, together with Timiş. On the opposite corner, Covasna, Giurgiu (only out-migrants), Harghita (only in-migrants) and Sălaj recorded the most reduced gross flows.

$i$. Absolute net migration. On average, 28 counties recorded negative balances while 14 recorded positive ones. The counties of Ilfov $(6,286$ persons), Timiş $(3,642)$, Cluj $(1,649)$, Arad $(1,342)$ and Constanța $(1,175)$ had the highest positive values of migratory balance, while the counties of Vaslui (-2,001 persons), Hunedoara (-1,714), Botoşani $(-1,324)$, Galați $(-1,203)$ and Olt $(-1,111)$ had the highest negative values. On the other side, Dâmbovița (20 migrants), Vrancea (52) and Mureş (-6) registered the lowest values of net migration flows. The capital, Bucharest, had an average balance of 670 migrants. More information in figure 3. 


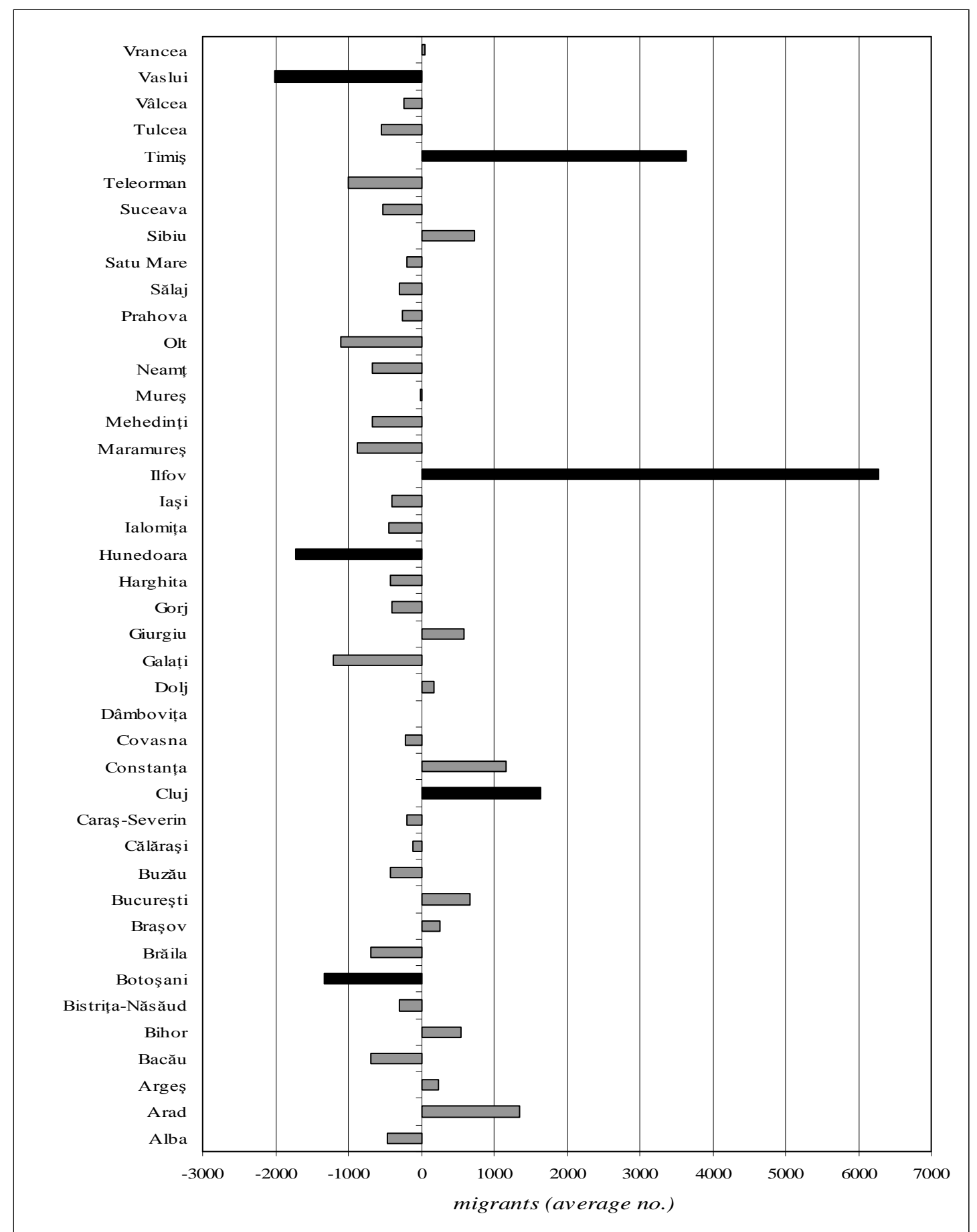

Figure no.3. Internal migration balance in absolute terms

Data Source: Romanian Statistical Yearbook 2005-2010/Ch. 2. Population

ii. Net migration rates. On average, Ilfov (21.89\%), Timiş (5.49\%), Arad (2.92\%o), Cluj (2.39\%o) and Giurgiu (2.05\%o) were the counties with the highest positive rates of net migration; while Vaslui $(-4.35 \%$ ) , Hunedoara $(-3.56 \%)$, Botoşani $(-2.89 \%$ ), Tulcea $(-2.36 \%$ ) and Olt ($2.30 \%$ ) had the highest negative rates. Finally, the counties of Dâmbovița $(0.004 \%$ ), Vrancea $(0.13 \%)$ and Mureș $(-0.01 \%$ ) recorded the least significant rates of migration. Bucharest registered a rate of $0.35 \%$ (fig. 4 ). 


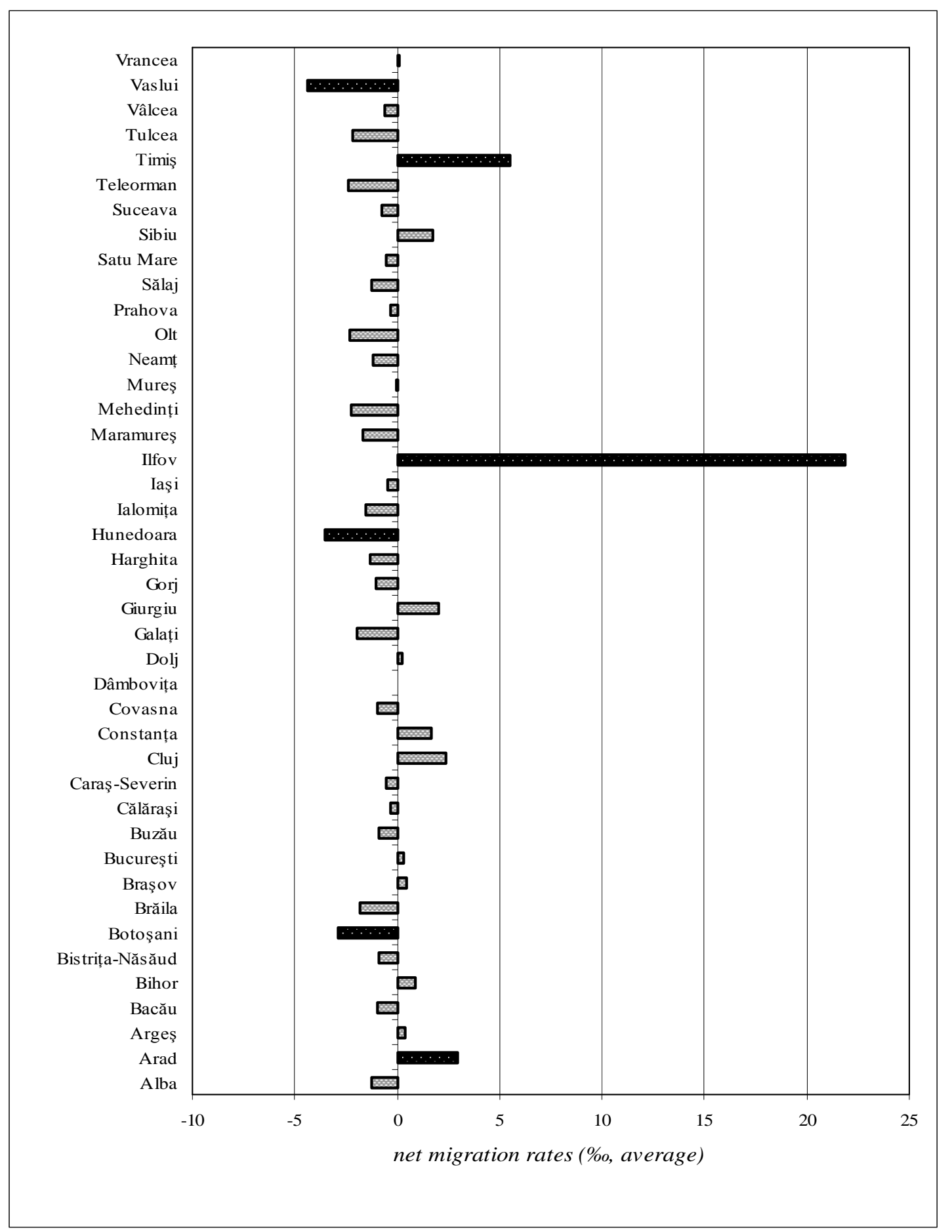

Figure no. 4. Internal migration balance in relative terms

Data Source: Romanian Statistical Yearbook 2005-2010/Ch. 2. Population

iii. Possible determinants of migration. The counties that registered the highest positive balances have in common employment rate (except for Giurgiu), rate of private dwelling (except for Constanța) and GDP per capita (except for Giurgiu) that all exceed the national average, while unemployment rate is below national average (less Giurgiu). Instead, the counties with the highest negative values resemble by employment rate (less Hunedoara), net monthly earnings, length of drinking water supply network (less Galați), length of distribution pipes of natural gas (less Hunedoara), schooling rate, GDP per capita, number of employees in research \& development (less Galați), and public expenditure per capita, whose values are below overall mean, while the values of 
unemployment rate (less Tulcea) and criminality rate are above overall average.

In order to see if the socio-economic condition of a county influences its rate of net migration, I have gathered a number of criteria (indicators) such as:

- population density (number of inhabitants per $\mathrm{km}^{2}$ );

- degree of urbanization (urban population divided by rural population);

- employment rate (number of civil employees divided by each county's total population);

- unemployment rate (number of registered unemployed divided by each county's active population);

- average net nominal monthly earnings (lei per employee);

- private dwelling rate (number of private dwellings per 1000 inhabitants);

- number of employees in the area of research \& development;

- criminality rate (number of persons definitively convicted per 100,000 inhabitants);

- density of public roads per $100 \mathrm{~km}^{2}$;

- schooling rate (total number of scholars divided by each county's total population);

- gross domestic product per capita;

- length of public sewerage pipes $\left(\mathrm{km}^{2}\right)$;

- urban green spaces area (ha);

- length of distribution pipes of natural gas $\left(\mathrm{km}^{2}\right)$;

- length of drinking water supply network $\left(\mathrm{km}^{2}\right)$;

- public expenditure per capita (lei per inhabitant).

Noting 1 each time a county records a criterion below national average 4 and 0 otherwise, I have obtained a total of 309 points for counties with negative migration balances and a total of 85 points for counties with positive balances. This means that counties with poor socio-economic situations register more outflows than inflows of migrants, while the richer and more prosperous counties experience average net inflows. In the next study, I intend to investigate which of the criteria above are significant in people's decision to migrate internally.

iv. Time evolution: 2009 versus 2004. In 2009 compared with 2004, the following counties experienced great fluctuations: Cluj and Dolj (increased their net inflows), Botoşani (augmented its net outflow), Ialomița and Gorj (passed from positive to negative), Dâmbovița (passed from negative to positive). On the other hand, the counties of Alba (decreased slightly its negative flow) and Sibiu (increased slightly its positive balance).

\section{County convergence in Romania regarding GDP and unemployment}

Usually, migrants move from regions with low incomes and high unemployment to regions with higher wages and better employment opportunities. This contributes to the adjustment to asymmetric shocks. But if the labour is rigid, the regional disequilibria will persist unless other mechanisms (e.g., fiscal) intervene.

Labour mobility is high in the US (Blanchard and Katz, 1992) and low in Europe (Decressin and Fatas, 1995). Moreover, in Central and Eastern Europe, the transition from central planning to market economy caused a series of regional disparities; here, labour mobility is even more crucial to help diminish them (Repkine and Walsh, 1999). These disparities are not important only internally, but also externally, for example, to enter the Economic and Monetary Union.

In European practice, regions with high wages tend to have high in-migration as well as high out-migration, rather than high in-migration and low out-migration. Similarly, unemployment seems to discourage both in-migration and out-migration, although its significance is, usually, lower than wages'. This is how regional disparities persist, because developed regions display high

\footnotetext{
${ }^{4}$ Here unemployment rate and criminality rate are not counted (with 1) because, theoretically, they have a negative influence on migration.
} 
migration (and persistent high wages and low unemployment) while depressed regions display low migration (and persistent high unemployment and low wages) (Fidrmuc, 2004). This is where the concepts of convergence (diminishing disparities) and divergence (increasing disparities) intervene.

\section{a. County convergence in GDP per capita}

Convergence can be explained by lower-income regions growing faster than higher-income regions, this is poorer regions catching up richer regions, and, as a consequence, regional disparities decreasing. On the contrary, divergence favors regional disparities (Barro et al, 1991, Roy and Montouri, 1998, etc.).

Regarding convergence there are two types of approaches: the traditional approach $(\sigma-$ convergence) and the neoclassical approach ( $\beta$-convergence) (Barro and Sala-i-Martín, 1992).

$\beta$-convergence is a necessary but not a sufficient condition for $\sigma$-convergence, or a negative/positive convergence parameter does not necessarily imply a declining/ascending crosssectional variance in GDP per capita levels ( $\sigma$-convergence) (Martin, 2000).

According to neoclassical view, convergence is due to diminishing returns to capital and constant returns to scale. Diminishing return to capital implies that the rate of return is negatively related to the stock of capital per head so that, caeteris paribus, regions with low amount of capital per head are expected to grow faster (Marques and Soukiazis, 1998).

In order to establish if a series is convergent, one should obtain a decreasing $\sigma$ convergence and a negative $\beta$-convergence, otherwise the series is divergent.

$\sigma$-convergence responds to question: "How the distribution of GDP per capita across regions behaved in the past or is likely to behave in the future?", whereas $\beta$-convergence responds to: "How fast and to what extent the GDP per capita of a certain region is likely to catch up to the national average?" (Barro et al., 1991).

Another classification of convergence distinguishes between (Martin, 2000):

- unconditional (strong, absolute) convergence: its study is more suited for regions of the same country which are more homogenous (they share the same legal system, similar technology, similar educational level, etc.); it assumes that all regions converge to the same steady-state point;

- conditional (weak, relative) convergence: its study is more appropriate when analysing convergence among countries due to their different structures; it assumes that countries converge to different steady-state points.

The present methodology has been applied by economists such as Barro and Sala-i-Martin (1991, 1992), Marques and Soukiazis (1998), Roy and Montouri (1998), Geppert et al. (2005), etc., but all concentrated on studying income convergence across US states, EU countries or EU regions. A similar case study such as the present was carried out by Hierro and Maza (2008) in order to detect if foreign-born internal migrants played any role in per capita income convergence in Spain.

$\sigma$-convergence is calculated using the coefficient of variation, the Gini index or the Theil index ${ }^{5}$ (fig. 5). The coefficient of variation increased by $35 \%$ in the period 2004-2008, the Gini index rose $26 \%$ while the Theil index rose $70 \%$. Because all indicators rose over time it seems that Romania passed through a process of increasing income disparities, i.e. divergence.

\footnotetext{
${ }^{5}$ These are the most indicators of inequality.
} 


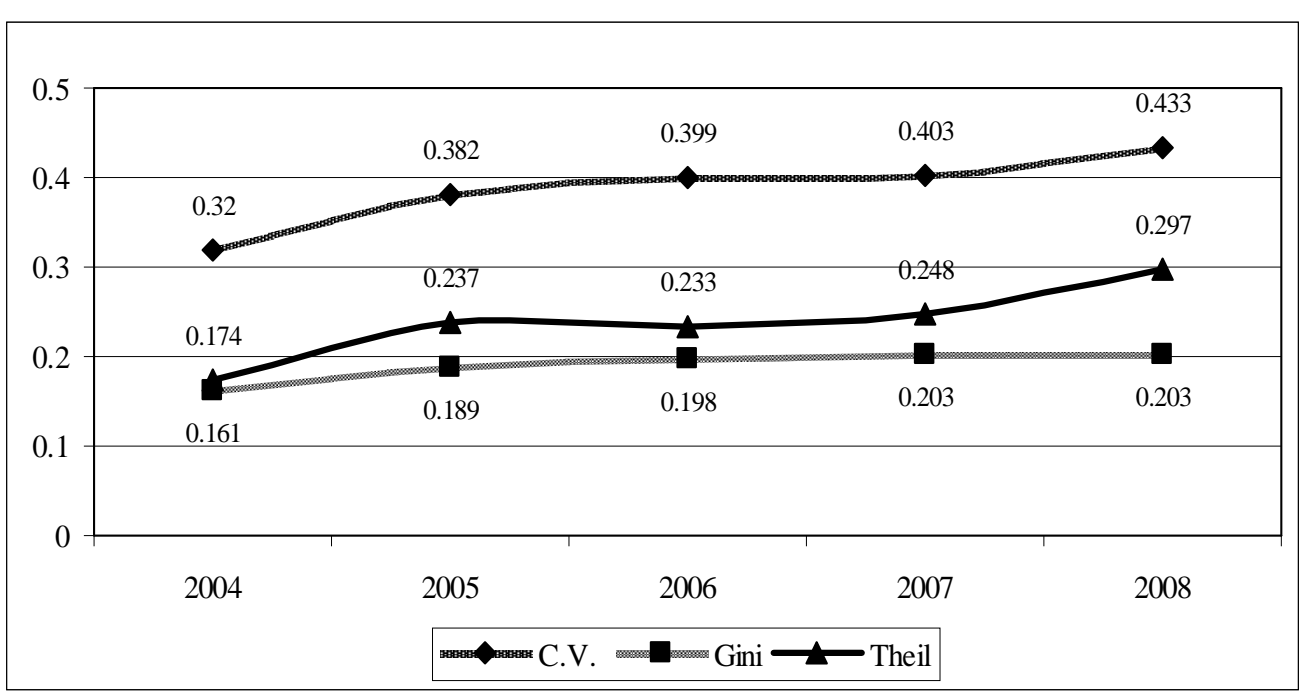

Figure no. 5.- $\sigma$-convergence for GDP per capita

To compute $\beta$-convergence, Barro and Sala-i-Martin (1991, 1992), followed by many others, employed the following non-linear regression model to study per capita income convergence:

$$
\log \left(\frac{g d p_{i 08}}{g d p_{i 04}}\right) / T=\alpha+\frac{\left(1-e^{-\beta T}\right)}{T} * \log g d p_{i 04}+\varepsilon_{i},
$$

where $g d p_{08}, g d p_{04}=$ per capita income in 2008 and 2004 (in 2004 prices), $\mathrm{i}=$ individual county, $\mathrm{T}$ $=$ period of time for which the growth of per capita income is calculated ( 4 years), $\alpha=$ constant term (autonomous or steady-state growth), $\beta=$ rate of convergence, $\varepsilon_{i}=$ the error term.

Applying this regression (using non-linear least square method) in Romania returns the following coefficients: $\alpha=-0.29$ and $\beta=4.6 \%$ (annual rate of divergence) (table 1(1)). The positive value of $\beta$ confirms the income divergence process in Romania, together with the ascending evolution of the indexes of inequality. In other words, the growth rates in per capita income over the four-year period are positively correlated with starting GDP levels.

Convergence studies also compute the convergence speed $(b)$ :

$$
b=-\frac{\ln (1+\beta T)}{T}=-4.22 \%
$$

Measuring convergence based on cross-sectional regressions, considering only the initial and last years, ignore any changes happened meanwhile. This is why Hierro and Maza (2010) employed a panel data analysis for Spain in order to capture the evolution of the distribution. According to them, one should include variables as the growth rate of per capita income in county $i$ during period $\mathrm{t}\left(g r_{i t}\right)$, as dependent variable, and per capita income during the previous period $\mathrm{t}-1$ $\left(g d p_{i, t-1}\right)$, as independent variable.

$$
g r_{i t}=\alpha+\beta * \log \left(g d p_{i, t-1}\right)+\mu_{i t}
$$

Testing this regression (unconditional convergence) for fixed or random effects and heteroskedasticity, the results confirm that there are no county effects and residuals are not serially correlated. Using ordinary least squares (OLS) method, I have obtained $\alpha=-0.34$ and $\beta=4.8 \%(b=-$ $4.39 \%$ ) (table 1(2)). Once again, I have got the confirmation of income divergence across Romanian counties.

Now let's see if internal migration has any influence on GDP per capita growth. To do this, I 
include in the model above the net migration rates for each county in the period $\mathrm{t}-1^{6}$ :

$$
g r 1_{i t}=\alpha+\beta^{*} \log \left(g d p_{i, t-1}\right)+\delta^{*} m r_{i, t-1}+\mu_{i t}
$$

This last type of convergence is a conditional $\beta$-convergence because I want to determine if migration has any impact on (conditions) the growth of per capita income. Theoretically, one should expect a negative $\delta$ coefficient because a high net migration should reduce per capita income growth. Applying OLS technique, I have got: $\alpha=-0.43, \beta=5.8 \% \quad(b=-5.21 \%), \delta=-0.1 \%$ (not significant) (table 1(3)). Hence, it seems migration had no consequence on GDP per capita growth.

Summarizing, the present analysis of GDP per capita convergence returned similar outcomes:

\section{GDP per capita convergence at county level}

Table no. 1.

\begin{tabular}{|c|c|c|c|}
\hline & (1) Non-linear LS & (2) Panel OLS 1 & (3) Panel OLS 2 \\
\hline$\alpha$ & -0.29 & $\begin{array}{c}-0.34 \\
\text { (p-value }=0.053)\end{array}$ & -0.43 \\
\hline$\beta$ & 0.046 & 0.048 & 0.058 \\
\hline$b$ & $-4.22 \%$ & $-4.39 \%$ & $-5.21 \%$ \\
\hline$\delta$ & - & - & $\begin{array}{c}-0.001 \\
(\mathrm{p}-\text {-value }=0.46)\end{array}$ \\
\hline$\overline{R^{2}}$ & 0.16 & 0.03 & 0.02 \\
\hline$D W$ & 1.96 & 2 & 2.01 \\
\hline
\end{tabular}

In conclusion, Romania experienced a divergence process in GDP per capita during the period 2004-2008 and internal migration has not played any role.

In order to strengthen the conclusion above, I also employed the standard stochastic kernel approach or the kernel density function, following the rule of Silverman (1986). Applying this rule, I can estimate the density functions (or distribution) for GDP per capita in 2004 and 2008. First, I had to transform GDP values in relative terms (national mean $=100$ ) in order to facilitate comparisons and eliminate the impact of absolute changes over time (Ezcurra and Pascual, 2006). The kernel density depicts us the changes occurred during the period 2004-2008.

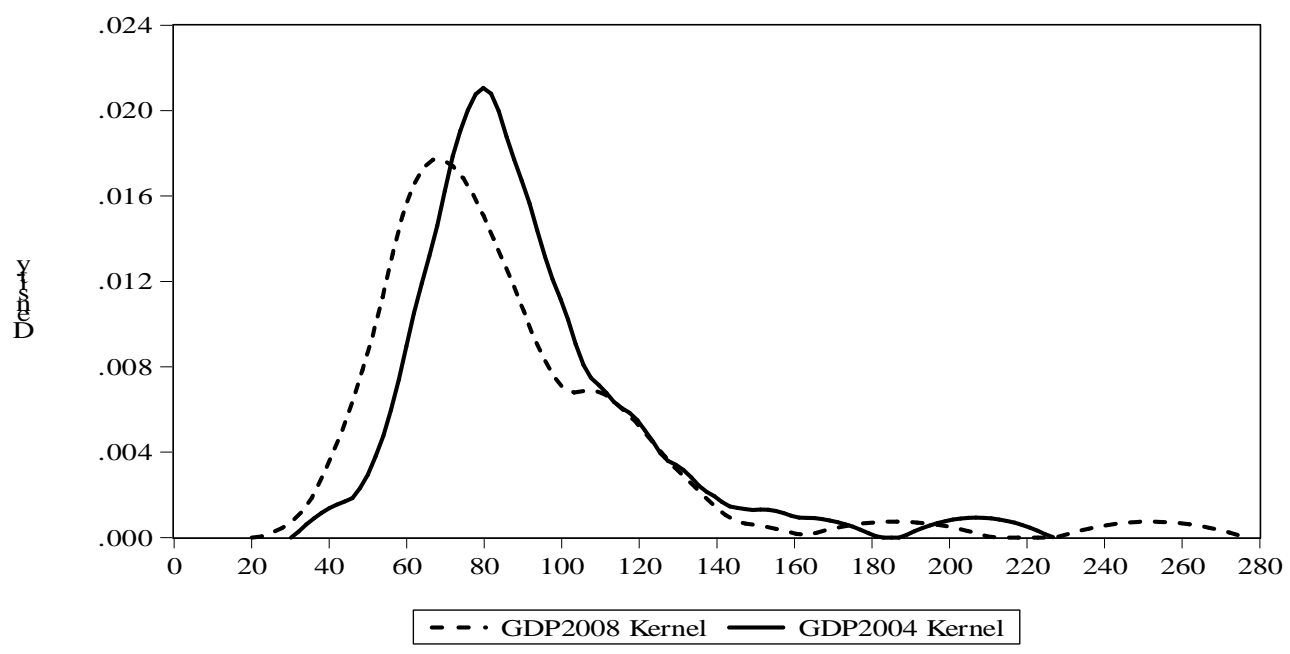

Figure no. 6. - Kernel density function for per capita income

\footnotetext{
${ }^{6}$ I can add many other variables supposed to influence local growth, but this is not the case here.
} 
The results obtained from figure 6 show the following:

- the dotted line of GDP2008 is below the continuous line of GDP2004, which means that there are less counties concentrated around the mean in 2008 than in 2004, i.e. divergence;

- the ratio of extreme values increased in 2008, i.e. divergence.

\section{b. County convergence in unemployment rates}

Applying the same methods as above to examine convergence in unemployment rates, I have obtained:

- All indexes rose in the period 2004-2009, but after, due to the economic crisis, fall even below their initial levels (fig. 7);

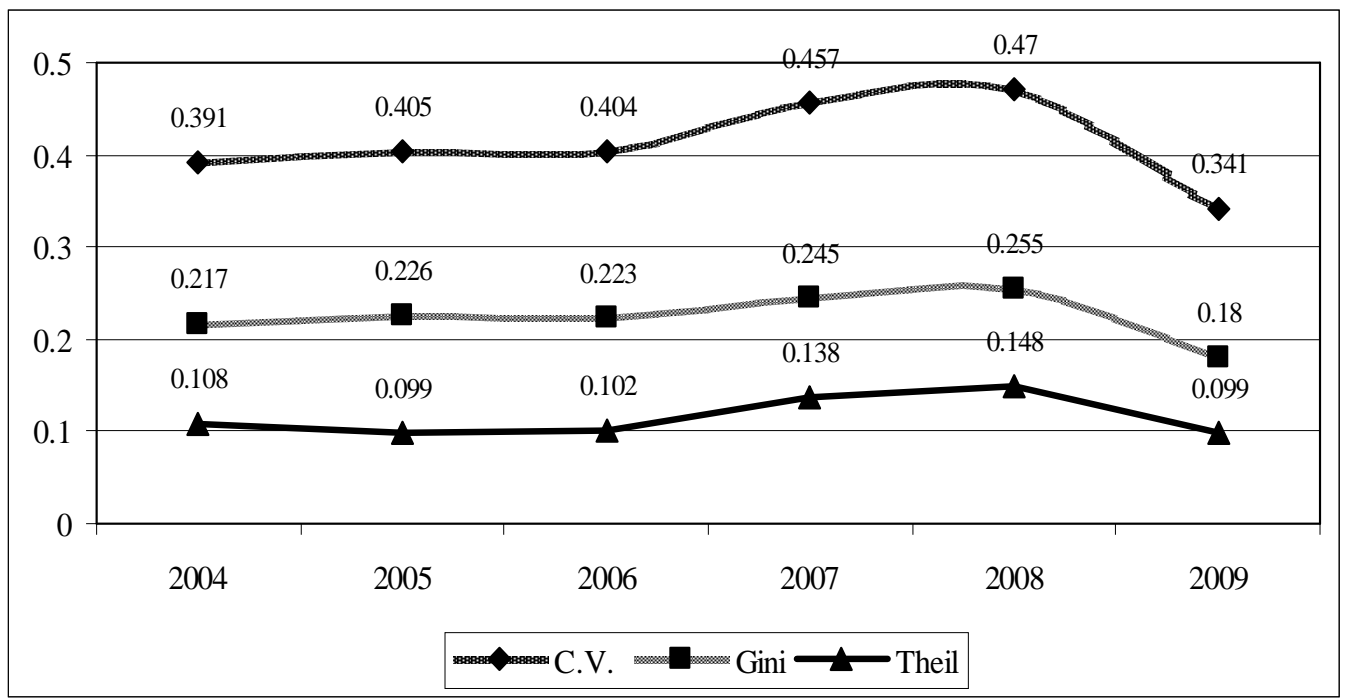

Figure no. 7. - $\sigma$-convergence for unemployment rate

- Econometric modelling using non-linear least squares (NLS) and panel data $\mathrm{OLS}^{7}$ returned the figures from table 2 :

Table no. 2

\section{Unemployment convergence at county level}

\begin{tabular}{|l|c|c|c|c|c|}
\hline $2004-2009$ & NLS & \multicolumn{2}{|c|}{ Panel OLS 1 } & \multicolumn{2}{c|}{ Panel OLS 2 } \\
\hline & & no fixed effects & period fixed effects & no fixed effects & period fixed effects \\
\hline$\alpha^{\prime}$ & 0.19 & 0.46 & 0.29 & 0.52 & 0.34 \\
\hline$\beta^{\prime}$ & -0.066 & -0.06 & -0.03 & -0.072 & -0.039 \\
\hline$b^{\prime}$ & $8 \%$ & $7.13 \%$ & $3.25 \%$ & $8.92 \%$ & $4.33 \%$ \\
\hline$\delta^{\prime}$ & - & - & - & -0.015 \\
& & & & 0.009 \\
\hline$\overline{R^{2}}$ & 0.28 & 0.09 & 0.77 & 0.10 & -0.009 \\
\hline$D W^{8}$ & 1.58 & 1.36 & 1.68 & 1.40 & 0.78 \\
\hline
\end{tabular}

Therefore, unemployment rates follow a convergence process $(\beta<0)$ proven by the severe decrease of inequality indexes in 2009 below their initial levels. Migration had a slight, but

\footnotetext{
${ }^{7}$ Here I used the following formula: $g r 2_{i t}=\alpha^{\prime}+\beta^{*} u r_{i, t-1}+\delta^{*} m r_{i, t-1}+\varepsilon_{i t}$, due to low values of the three variables.

${ }^{8}$ No serial correlations after verifying with LM test.
} 
significant (at least for $10 \%$ threshold), negative influence on annual unemployment growth $(\approx 1 \%)$. Also, it should be noted that, after the introduction of the migration variable, the annual speed of convergence goes up from $7.13 \%(3.25 \%)$ to $8.92 \%(4.33 \%)$.

- Applying the kernel density function, the result comes to confirm the convergence process, because the dotted line of UR2009 is superior to the continuous line of UR2004, which means that there are more counties concentrated around the national mean (100) in 2009 than 2004 (fig. 8).

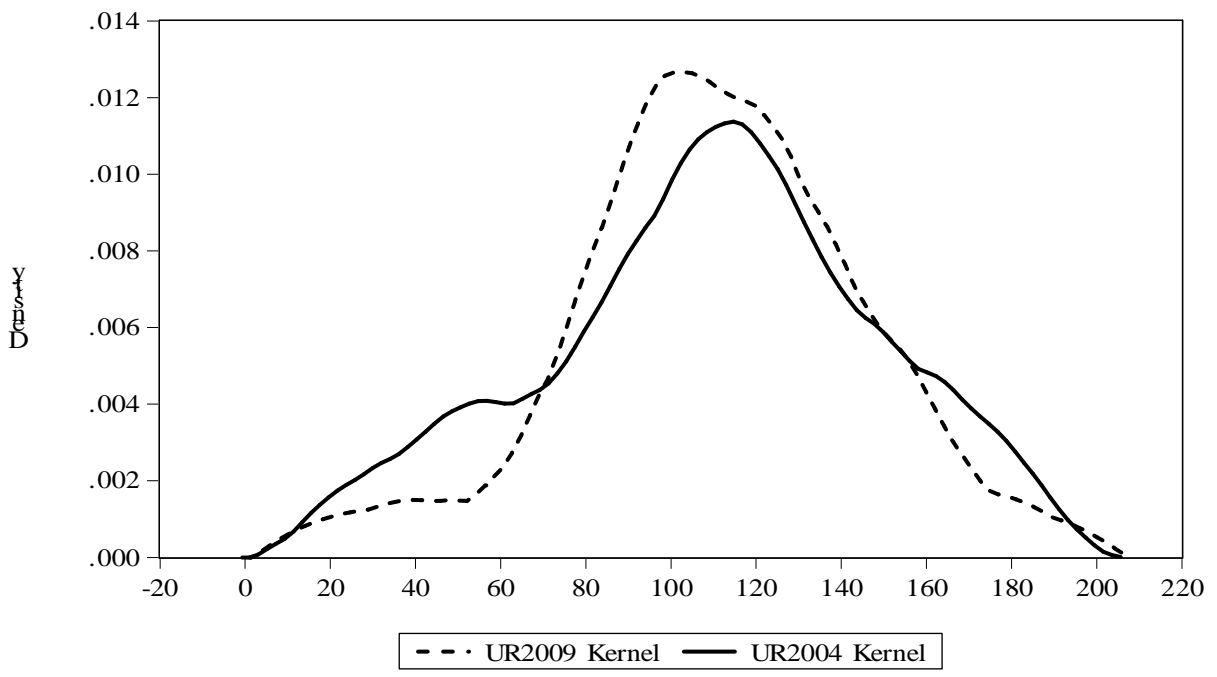

Figure no. 8. - Kernel density function for unemployment rate

\section{Conclusion}

In this paperwork I have tried to determine the degree of labour mobility within Romanian borders and to see if mobility levels have any impact on GDP per capita and unemployment rate divergence or convergence directions. As a consequence, net migration rates graph showed that there were quite small rates across counties in the period 2004-2009. In a future study, I intend to identify the causes of this rigidity. As for convergence, the evidence, using 4 different methods, revealed that per capita income suffered a divergence process in the period mentioned whilst unemployment rate, on the contrary, witnessed a convergence process. Migration had only a very small influence on unemployment convergence and none on income divergence.

\section{Acknowledgement}

This article is carried out under the project " $\mathrm{PhD}$ in Economics at Standards of the Europe of KnowledThis article is a result of the project POSDRU/88/1.5./S/55287 "Doctoral Programme in Economics at European Knowledge Standards (DOESEC)". This project is co-funded by the European Social Fund through The Sectorial Operational Programme for Human Resources Development 2007-2013, coordinated by The Bucharest Academy of Economic Studies in partnership with West University of Timisoara."

\section{References}

1. Barro J. R. et al., 1991. Convergence across states and regions, Brookings Papers on Economic Activity, vol. 1991, pp. 107-182

2. Barro J. R., Sala-i-Martin X., 1992. Convergence, Journal of Political Economy, vol. 100, pp. 223251

3. Blanchard O. J., Katz L. F., 1992. Regional evolutions, Brookings Papers on Economic Activity, vol. 1, pp. 1-61 
4. Borjas G. J., 2008. Labor economics, Ed. 4. New York, McGraw-Hill/Irwin

5. Decressin J., Fatas A., 1995. Regional labour market dynamics in Europe, European Economic Review, vol. 39, pp. 627-1655

5. Etzo I., 2008. Internal migration: a review of the literature, MPRA Paper 8783, University Library of Munich, Germany, available online at http://mpra.ub.uni-muenchen.de/8783/

6. Ezcurra R., Pascual P., 2006. Factor decomposition of spatial disparities: The case of the European regions, Economic Bulletin, vol. 18, pp. 1-6

7. Fidrmuc J., 2004. Migration and regional adjustment to asymmetric shocks in transition economies, Journal of Comparative Economics, vol. 32, pp. 230-247

8. Geppert K. et al., 2005. Regional disparities in the European Union: Convergence and agglomeration, Discussion Papers of DIW Berlin 525, German Institute for Economic Research, available online at http://www.diw.de/documents/publikationen/73/diw_01.c.43804.de/dp525.pdf

9. Greenwood M. J., 1997. Internal migration in developed countries (Ch. 12), in Rosenzweig, M. R. and Stark, O. (eds.), 1997, Handbook of Population and Family Economics, vol. 1B, Amsterdam, Elsevier

10. Hicks,J. R., 1932. The theory of wages. London, Macmillan

11. Hierro M., Maza A., 2010. Foreign-born internal migrants: are they playing a different role than natives on income convergence in Spain?, Applied Geography, vol. 30, pp. 618-628

12. Jackman R., Savouri S., 1992. Regional migration in Britain: An analysis of gross flows using NHS central register data, Economic Journal, vol. 102, pp. 1433-1450

13. Jennissen R., 2007. Causality chains in the international migration systems approach, Population Research and Policy Review, vol. 26, pp. 411-436

14. Lee E.S., 1966. A theory of migration, Demography, vol. 3, pp. 47-57

15. Marques A., Soukiazis E., 1998. Per capita convergence across countries and across regions in the European Union. Some new evidence., $2^{\text {nd }}$ International Meeting of European Economy, CEDIN (ISEG), Lisbon

16. Martin R., 2000. EMU versus the regions? Regional convergence and divergence in Euroland, ESRC Centre for Business Research, University of Cambridge, Working Paper no. 179

17. Molho I., 1986. Theories of migration: a review, Scottish Journal of Political Economy, vol. 33, 1986, pp. 396-419

18. Ravenstein E.G., 1885. The laws of migration, Journal of the Royal Statistical Society, vol. 48, pp. $167-235$

19. Ravenstein E.G., 1889. The laws of migration, Journal of the Royal Statistical Society, vol. 52, pp. 241-305

20. Repkine A., Walsh P. P., 1999. Evidence of European trade and investment U-shaping industrial output in Bulgaria, Hungary, Poland, and Romania; Journal of Comparative Economics, vol. 27, pp. 730-752

21. Rey S. J., Montouri B. D., 1998. US regional income convergence: A spatial econometric perspective, Regional Studies, vol. 33, pp. 143-156

22. Riadh B. J., 1998. Rural-urban migration: on the Harris-Todaro model, http://www.arabapi.org/cv/riyadh-cv/pdf/Riadh3.pdf, 28 August 2011

23. Silverman B. W., 1986. Density estimation for statistics and data analysis. London, Chapman and Hall

24. Silvers, A., 1977. Probabilistic income maximizing behaviour in regional migration, International Regional Science Review, vol. 2, pp. 29-40.

25. Van der Gaag N. et al., 2003. Study of past and future interregional migration trends and patterns within European Union countries in search of a generally applicable explanatory model, Report on behalf of Eurostat.

26. Eurostat website, http://epp.eurostat.ec.europa.eu/portal/page/portal/nuts_nomenclature/, 3 August 2011

27. Romanian Statistical Yearbook 2005-2010

28. www.cursdeguvernare.ro, 9 August 2011.

29. www.insse.ro/TEMPO-Online (Romanian National Institute of Statistics), 15 August 2011. 